\title{
O STF NAS “CORTES”VICTOR NUNES LEAL, MOREIRA ALVES E GILMAR MENDES
}

\author{
Siddharta Legale Ferreira e Eric Baracho Dore Fernandes
}

THE BRAZILIAN FEDERAL SUPREME COURT UNDER VICTOR NUNES LEAL, MOREIRA ALVES AND GILMAR MENDES

\section{RESUMO}

O TEXTO TEM COMO OBJETIVO ESTUDAR A HISTÓRIA RECENTE DO SuPREMo TRIBUNAL FEDERAL A PARTIR DE TRÊS MOMENTOS QUE BATIZAMOS DE "CORTES" COM OS NOMES DE CERTOS MINISTROS DO STF, QUE PODEM SER CONSIDERADOS METONIMIAS DA JURISDIÇÃO CONSTITUCIONAL DE SUA ÉPOCA. O PRIMEIRO, "A CORTE VICTOR NUNES LEAL", TRATARÁ BREVEMENTE DE UM PERÍODO CONTURBADO PARA A JURISDIC̄ÃO CONSTITUCIONAL DURANTE A DITADURA MILITAR. O segundo, a "Corte Moreira Alves", volta-se para o MOMENTO LOGO APÓS A CONSTITUIÇÃO DE 1988, COM UM PERFIL defensivo. O terceiro, "A CoRTe GILMAR Mendes", IDENTIFICA 0 PROCESSO DE JUDICIALIZAÇÃO DA POLÍTICA E DA VIDA, BEM COMO UM MAIOR ATIVISMO JUDICIAL. A METODOLOGIA EMPREGADA CONJUGA UMA PESQUISA BIBLIOGRÁFICA DAS OBRAS DOS MINISTROS CITADOS, BEM COMO DE ALGUMAS DAS MAIS IMPORTANTES DECISÖES DO PERÍODO EM QUE INTEgRAVAM A CORTE. ESPERA-SE APRESENTAR, COM ISSO, UMA RADIOGRAFIA DA JURISDIÇĀO CONSTITUCIONAL BRASILEIRA DAS ÚLTIMAS DÉCADAS.

\section{PALAVRAS-CHAVE}

SUPREMo Tribunal FEDERAL; JURISPRUdÊNCIA; JURISDIC̣Āo

Constitucional; Direito Constitucional; Poder Judiciário.

\section{ABSTRACT}

THIS WORK SEEKS TO STUDY THE FEDERAL SUPREME COURT'S RECENT HISTORY DURING THREE MOMENTS WE HAVE DECIDED TO CALL "COURTS", NAMED AFTER SOME OF ITS JUSTICES WHO REPRESENT THE MAIN CHARACTERISTICS OF THE JUDICIAL REVIEW OF THEIR TIMES. THE FIRST, "VICTOR NUNES LEAL COURT", BROACHES A HARD TIME FOR JUDICIAL REVIEW DURING THE MILITARY DICTATORSHIP IN BRAZIL, AS WELL AS THE ADVENT OF THE SUMMARIES OF JURISPRUDENCE by the Federal Supreme Court. The second moment, "MoReIRA ALVES COURT", WILL SHOW A MOMENT OF SELFRESTRAINT FOR THE JUDICIAL REVIEW. THE THIRD ONE,

"GILMAR MENDES COURT", SHOWS A MOMENT OF GREATER JUDICIAL ACTIVISM OF THE JUDICIAL BRANCH REGARDING THE JUDICIAL REVIEW OF LEGISLATION. THE MAIN GOAL OF THIS PAPER IS TO MAKE AN ANALYSIS OF BRAZIL'S JUDICIAL REVIEW OVER THE LAST DECADES.

\section{KEYWORDS}

FEDERAL Supreme Court; Judicial ReVIeW; Constitutional LaW; Judicial BRANCH.

\section{INTRODUÇÃO}

Não é comum no Brasil acompanhar a jurisprudência a partir da figura de um Ministro, seja para compreender o seu desempenho, seja para compreender uma fase de um Tribunal. De um lado, diferentemente da tradição norte-americana, são raros ou muito recentes os estudos de casos ou reflexões de maior fôlego e, de outro lado, nossas instituições são, de fato, diferentes: o Chief Justice dos EUA não 
tem o mesmo papel que o Presidente do STF. O tempo em que permanecem como Presidentes das Cortes e as funções desempenhadas são mesmo diferentes. Por aqui, o cargo de Ministro é exercido vitaliciamente, mas a função de Presidente dáse por dois anos de forma rotativa (DUARTE; GODINHO, 2007, p. 41-59). Apesar disso, é possível transcender a limitação temporal e, fazendo algumas concessões metodológicas, reconhecer a existência do que denominamos de três momentos batizados de "Cortes" com os nomes de certos ministros do Supremo Tribunal Federal, que podem ser considerados metonímias do perfil da jurisdição constitucional de sua época: a "Corte Victor Nunes Leal", a "Corte Moreira Alves" e a "Corte Gilmar Mendes".

O primeiro, a "Corte Victor Nunes Leal”, tratará brevemente de um período conturbado para a jurisdição constitucional na ditadura militar, durante o qual se destacou a contribuição de um Ministro a um só tempo capaz de defender ativamente a democracia em um momento de hipertrofia institucional do Executivo e também introduzir um instrumento de trabalho capaz de tornar a atuação do Supremo mais isonômica, racional e célere: a súmula da jurisprudência dominante.

O segundo momento, a "Corte Moreira Alves", volta-se para o perfil da jurisdição constitucional logo após a Constituição de 1988, com um perfil defensivo. José Carlos Moreira Alves, em 20 de junho de 1975, foi nomeado por indicação do Presidente da República Ernesto Geisel para o cargo de Ministro do Supremo Tribunal Federal, em razão da aposentadoria do Ministro Oswaldo Trigueiro de Albuquerque Mello. O Ministro permaneceu no STF até 19 de abril de 2003, quando atingiu a idade limite de setenta anos para atividade na Corte. Foi sucedido pelo Ministro Joaquim Barbosa, chegando a ter exercido - respeitando as exigências constitucionais e legais - a Presidência dos três Poderes. Esse período de mais de duas décadas de judicatura federal e principalmente constitucional - com certas concessões metodológicas, como dito - será designado a "Corte Moreira Alves”. Percebe-se, no período, a transição de um controle por meio da representação de inconstitucionalidade para um modelo abstrato complexo, dotado de uma gama de ações e técnicas de tomada de decisão. Foi nesse período que se definiu, por exemplo, que o controle de constitucionalidade é um processo objetivo, sem interesses subjetivos $a$ priori, que não o de preservar a normatividade da Constituição, bem como se consolidou o efeito erga omnes da ação direta de inconstitucionalidade e o mandado de injunção recebeu efeitos não concretistas.

O terceiro, a "Corte Gilmar Mendes", identifica o processo de judicialização da política e da vida, bem como um maior ativismo judicial. Destaca-se, especialmente o período em que o Ministro Gilmar Mendes ocupou a função de Presidente da Corte entre 2008 e 2010, ao qual chamamos de a "Corte Gilmar" (AMARAL, 2010). Não bastasse isso, o Ministro Gilmar Mendes foi um dos principais responsáveis por conduzir a discussão acadêmica sobre o controle de constitucionalidade a um patamar mais 
elevado. O ministro colaborou, ainda, com a redação das principais leis de controle de constitucionalidade (Lei n. 9.868/99 e Lei n. 9.882/99). Nota-se, no período, que o Presidente do STF cada vez mais tem exercido um papel político importante que imprime suas marcas na saga da jurisdição constitucional, bem como acaba por influenciar em direção a um maior ou menor ativismo judicial, o que é perceptível pela atribuição de efeitos concretistas ao mandado de injunção, no estabelecimento do prazo para o legislativo sanar a omissão da regra do art. $18, \S 4^{\circ}$, e no aumento acelerado na edição de súmulas vinculantes.

A metodologia empregada conjuga uma pesquisa bibliográfica das obras dos ministros citados, bem como de algumas das mais importantes decisões do período em que integravam a Corte. Espera-se apresentar, com isso, uma radiografia da jurisdição constitucional brasileira das últimas décadas de modo a melhor compreender etapas significativas da construção das instituições contemporâneas.

\section{A "CORTE Victor Nunes LeAL":}

A DEFESA DE UMA CORTE SUPREMA DEMOCRÁTICA EM TEMPOS DE DITADURA

E A RACIONALIZAÇÃO DA JURISDIÇÃO CONSTITUCIONAL

Já não é novidade dizer que, sob a vigência da Constituição de 1988, o Poder Judiciário passou de coadjuvante a protagonista no cenário político brasileiro, decidindo com independência questões relevantes não só do ponto de vista jurídico, mas também político. Todavia, que hoje se observa de forma tão evidente no cenário nacional não foi fruto de um processo imediato. Pelo contrário, tal papel de "reinvenção da Constituição" (SAMPAIO, 2002, p. 9-43) somente pôde ser atribuído à jurisdição constitucional por meio de um longo processo histórico de luta pelas instituições democráticas e construção de ferramentas jurídicas capazes de operacionalizar de forma efetiva as transformações necessárias ao exercício efetivo da função jurisdicional, em especial pelo Supremo Tribunal Federal. É dentro desse processo que se destaca o legado deixado pelo Ministro Victor Nunes Leal ao direito brasileiro, cuja atuação foi não somente independente em face da hipertrofia do Executivo de seu tempo, mas também foi significativa com a criação de um dos mais relevantes instrumentos de trabalho do Judiciário na atualidade: as súmulas.

Victor Nunes nasceu em 1914, em Carangola, Minas Gerais. Ainda jovem, mudou-se para o Rio de Janeiro, onde se dedicou ao estudo da advocacia, sendo acolhido por Pedro Batista Martins, que mais tarde se consagraria como autor do Código de Processo Civil de 1932. Após concluir o bacharelado em 1936, passou a exercer a advocacia, e, ao mesmo tempo, a compor a equipe de Gustavo Capanema, no Ministério da Educação. Também nesse período, compôs o conselho editorial da Revista de Direito Administrativo e Forense, duas das revistas jurídicas mais tradicionais. Os trabalhos que publicou até década de 1960, em especial na Revista de Direito 
Administrativo, viriam a compor a obra Problemas de direito público, que reúne diversos trabalhos notáveis sobre poder discricionário e controle jurisdicional.

Antes de construir seu legado como ministro do Supremo Tribunal Federal, Victor Nunes o fez na academia, sendo sua trajetória como professor essencial para a construção de sua obra-prima, Coronelismo, enxada e voto. Sua carreira como docente teve início na Universidade do Distrito Federal, que mais tarde foi extinta e incorporada à Universidade de Brasília. Victor Nunes foi indicado em 1943 para preencher a cadeira de ciência política, cujo titular anterior foi o professor André Grós. Durante os três anos seguintes, dedicou-se integralmente ao magistério, preparando a tese do concurso para professor titular, cujo título era $O$ município e o regime representativo no Brasil Contribuição ao estudo do Coronelismo. Aprovada com grau máximo, sua tese se transformou no clássico Coronelismo, enxada e voto. Como acadêmico, Victor Nunes Leal demonstrava ser talentoso tanto como cientista político quanto como jurista (LEAL, 1948). Além do clássico Coronelismo, enxada e voto, Victor Nunes produziu diversos escritos de direito administrativo e, em maior relevo, direito constitucional, em uma época em que o estudo da matéria era colocado em segundo plano pela maior parte dos juristas. Destacam-se, por exemplo, seus estudos pioneiros sobre os efeitos da inconstitucionalidade superveniente de normas, na vanguarda da corrente doutrinária que acabou por prevalecer, tempos mais tarde (BARROSO, 2009, p. 77).

A vida acadêmica não o afastou da prática política. Após a participação na militância pela defesa da legalidade, movimento liderado por Sobral Pinto na defesa da eleição e posse de Kubitschek contra as ameaças de golpe militar da época, Victor Nunes participou do governo de Juscelino, primeiro como Procurador-Geral de Justiça do Distrito Federal e, em seguida, como Chefe da Casa Civil, de 1956 a 1959. Seu maior legado, contudo, foi deixado por sua passagem pelo Supremo Tribunal Federal, no qual foi empossado em 1960, após breve passagem pela ConsultoriaGeral da República.

Em 16 de janeiro de 1969, Victor Nunes foi aposentado compulsoriamente do Supremo Tribunal Federal por decreto baseado no Ato Institucional n. 5, de 13 de dezembro de 1968. A vaga por ele deixada não foi preenchida em razão da superveniência do Ato Institucional n. 6, de $1^{\circ}$ de fevereiro de 1969, que reduziu de 16 para 11 o número de Ministros do STF, aposentando compulsoriamente também os ministros Antônio Carlos Lafayette de Andrada e Antônio Gonçalves de Oliveira, que haviam se manifestado contra a cassação de outros ministros do tribunal: além de Victor Nunes Leal, Hermes Lima e Evandro Lins e Silva. Nesse momento de extrema fragilidade das instituições democráticas e hipertrofia do Poder Executivo, não é difícil compreender o porquê das posições de Victor Nunes Leal em defesa da soberania popular representarem uma ameaça ao regime vigente à época. Foram selecionados, a seguir, dois julgados da época, nos quais Victor Nunes participou e que demonstram de forma mais clara tal aspecto de sua atuação. 
No Habeas Corpus n. 41.296, o paciente, governador Mauro Borges, alegava que adversários políticos oriundos do governo militar haveriam forjado provas de supostos atos subversivos, para afastá-lo do poder e submetê-lo ao julgamento pela Justiça Militar. Esta, em tese, seria competente, em virtude do enquadramento das supostas "atividades subversivas" do Governador, aos crimes de responsabilidade definidos na Lei n. 1.079/50 que seriam de competência da Justiça Militar, em face do disposto na Lei de Segurança Nacional. Segundo o impetrante, o remédio deveria ser concedido para que ele fosse julgado no foro por prerrogativa de sua função: Assembleia Legislativa, em casos de crime de responsabilidade, e Tribunal de Justiça, por crimes comuns. A ordem foi concedida pelo relator, Gonçalves de Oliveira, acompanhado por unanimidade. Deixando de lado as controvérsias trabalhadas no julgado, destacam-se as ponderações tecidas pelo Ministro Victor Nunes Leal, em defesa da autonomia do ente da federação em face de eventuais ingerências do poder central, o que reflete a preocupação com um federalismo mais democrático. Victor Nunes Leal comparou tal hipótese a uma verdadeira forma indireta de intervenção federal.

Outro julgado interessante demonstra o entendimento de Victor Nunes Leal acerca da natureza jurídica dos atos institucionais e decretos-lei e a competência do STF na apreciação de atos autoritários em sede de mandado de segurança. O leading case que firmou o posicionamento de Victor Nunes foi o Mandado de Segurança n. 17.957. O writ em questão fora impetrado pela Companhia de Docas da Bahia contra o Decreto-Lei n. 128/67, que havia criado anteriormente à Constituição de 1967 restrições ao exercício de certos direitos sobre terrenos de marinha e seus acrescidos. Duas questões preliminares foram objeto da controvérsia mais relevante para a solução do caso concreto. A primeira diria respeito à natureza do decreto-lei como lei em tese, de modo que na hipótese se aplicaria a Súmula n. 266 do STF. A segunda controvérsia referia-se ao art. 173 da Constituição de 1967, que excluía da apreciação do Poder Judiciário “os atos praticados pelo Comando Supremo da Revolução de 31 de março de 1964", listando, em especial, atos com base nos Atos Institucionais n. 1, 2, 3 e 4 (incluindo-se aí o referido Decreto-Lei n. 128/67). O relator, Aliomar Baleeiro, e os demais Ministros se posicionaram no sentido de que se tratava de lei em tese, e, como tal, dentro do âmbito de incidência da referida Súmula. Além disso, entenderam que a regra contida no art. 173 da Constituição em vigor afastaria do Supremo Tribunal Federal a possibilidade de analisar a pretensão do impetrante. Victor Nunes Leal, contudo, ousou divergir, ainda que tenha restado vencido.

Quanto à primeira questão, em um primeiro momento, Victor Nunes concordou com o voto do relator, porém apresenta divergência no sentido de que determinadas leis, ainda que em abstrato, poderiam ser impugnadas pela via do mandado de segurança. Isso ocorreria, segundo o Ministro, com certas leis proibitivas, que poderiam ferir o direito líquido e certo independentemente de ato de execução. Porém a real demonstração de coragem de Victor Nunes Leal ocorreu em relação à segunda controvérsia. O 
Ministro consignou de forma expressa a impossibilidade de se extrair qualquer interpretação da Constituição no sentido de que seria possível afastar da apreciação judicial um ato manifestamente contrário ao texto constitucional. Não seria possível para aquilo que ele chamou de "Poder Revolucionário" imunizar o conteúdo de qualquer legislação pré-constitucional, ainda que contrariasse a Constituição, sob pena de se reconhecer a existência de dois regimes constitucionais distintos, um composto pelas normas formalmente constitucionais da Constituição de 1967 e outro pelos atos do Executivo. Não poderia haver, em suas palavras, "outro sistema de normas que o Supremo Tribunal tenha de aplicar contra a letra e o espírito da Constituição". A despeito de o art. 173 da Constituição outorgada de 1967 ter tentado excluir determinados atos do Executivo da apreciação do Judiciário, Victor Nunes Leal entendeu que tais atos não poderiam ser recepcionados no que contrariassem a Constituição vigente. Afirmou que "o país não teria sido constitucionalizado pela metade", sendo impossível conceber a existência de duas ordens constitucionais distintas, frustrando, portanto, as tentativas do Governo Militar em imunizar seus atos diante do texto constitucional. Defendeu Victor Nunes Leal que, a despeito da vigência formal do art. 173, isso não impediria que se analisasse, casuisticamente, o conteúdo de atos do Executivo em concreto e sua compatibilidade com a nova ordem constitucional. No entanto, Victor Nunes restou vencido na ocasião, tendo o relator e os demais Ministros votado em sentido contrário.

A luta pela preponderância do Estado Democrático de Direito foi a marca de Victor Nunes Leal como Ministro. Isso pode ser claramente percebido em outras ocasiões nas quais manifestou entendimento sobre a natureza jurídica dos Atos Institucionais. Em julgamento histórico no Supremo Tribunal Federal (Inquérito n. 2), discutia-se qual o tribunal ou juízo seria competente para julgar o antigo Presidente da República João Goulart, acusado em inquérito policial militar da prática de crimes comuns durante o exercício do cargo, e que teve seus direitos políticos suspensos com fundamento no Ato Institucional n. 2. A dúvida era: seria a competência da Justiça Militar, com base no referido Ato, ou do Supremo Tribunal Federal, com base na Constituição em vigor? Além da previsão da competência da Justiça Militar para julgamento dos crimes contra a segurança nacional, o art. 16 do AI 2 fazia cessar o foro por prerrogativa de função de quem tivesse seus direitos políticos suspensos. E ao mesmo tempo em que a Constituição de 1967 previa o foro por prerrogativa de função (art. 114), afastada da apreciação judicial os Atos Institucionais e seus efeitos (art. 173). Colhidos todos os votos dos presentes, a questão restou empatada. Diante disso, o Presidente questionou se nesse caso não teria sido alcançada a maioria necessária para declarar a inconstitucionalidade superveniente do AI 2. E aí surge questão de ordem em plenário sobre a natureza jurídica dos atos institucionais após a Constituição de 1967: se seriam mantidos como normas de conteúdo constitucional ou recepcionados como de hierarquia legal. Na controvérsia em questão, 
o Ministro Victor Nunes Leal relembrou o voto proferido no caso da Companhia de Docas da Bahia, destacando ser impossível que qualquer norma anterior, de conteúdo supostamente constitucional, pudesse coexistir com a Constituição de 1967. Todavia, tal entendimento não predominou, tendo sido mantidos os efeitos do Ato Institucional n. 2 e, portanto, a competência da Justiça Militar para julgamento do feito.

Como se pode notar, mesmo votando vencido, o Ministro Victor Nunes Leal reiteradamente demonstrou insatisfação diante da ideia de imunizar atos do Executivo do controle jurisdicional de compatibilidade com a Constituição. Esse voto assume o peso histórico inigualável e se torna representativo de toda uma época: período em que era preciso construir a democracia, um Judiciário independente e resistir por mais custoso que fosse ao estado autoritário. Outro legado dos mais importantes de Victor para a Corte Suprema se deu por meio de uma contribuição específica. Contribuição esta que, desde sua instituição, tem servido como valioso método de trabalho e ferramenta capaz de dotar as decisões dos tribunais de isonomia, segurança e celeridade: as súmulas de jurisprudência dominante.

Não são recentes as tentativas de uniformizar e racionalizar a atividade jurisdicional. O volume de julgados de uma corte será sempre maior do que a capacidade de um indivíduo compreendê-la e captá-la em toda a sua abrangência. Cada época procurou, por isso, dar a sua contribuição, de modo a simplificar as ideias centrais que guiaram a jurisprudência para que esta fosse mais facilmente operada pelos juristas e advogados, tornando-se mais racional e isonômica quando aplicada aos jurisdicionados. Diversas razões deram ensejo à criação do instituto por Victor Nunes Leal, dentre as quais duas costumavam ser apontadas pelo Ministro como principais. A primeira delas era de razão prática. Segundo testemunhos do próprio Victor Nunes, havia grande dificuldade para que os ministros identificassem as matérias em que a jurisprudência estava pacificada e aquelas que ainda mereciam discussão aprofundada (LEAL, 1981, p. 294). A utilização de uma súmula, com enunciados sintéticos e capazes de consubstanciar a essência do entendimento anteriormente firmado, atenuaria essa dificuldade de ordem prática. Em um comentário curioso, Victor Nunes atribuiu a origem das súmulas à sua própria falta de memória. A segunda razão, no entanto, foi o grande volume de processos oriundos de temas repetitivos, que congestionavam o Supremo Tribunal Federal, situação que Victor associava a um "fardo asfixiante" e "a uma fábrica montada para fazer dos juízes estivadores” (LEAL, 1981, p. 294). Nesse contexto, as súmulas surgem em face da necessidade de um mecanismo de trabalho que possibilitasse ao STF abreviar o julgamento dos processos repetitivos, e se deter sobre aquelas que demandassem por uma análise qualitativa mais densa.

Se o Ministro Victor Nunes Leal, o criador das súmulas de jurisprudência dominante no Supremo Tribunal Federal, tivesse a oportunidade de enxergar hoje onde 
foi parar o seu pontapé inicial, custaria a acreditaria que, transcorridos aproximadamente 30 anos, a realidade é irremediavelmente outra: já são 736 súmulas tradicionais e 32 súmulas com um inesperado efeito vinculante para Administração e demais órgãos do Poder Judiciário. Não há como voltar atrás. Não há porque voltar atrás. Maior perplexidade e felicidade, Victor teria em ver que magistrados não são mais aposentados compulsoriamente pelo ditador de plantão. Pelo contrário, as nomeações para Ministro do STF são feitas pelo Presidente da República, democraticamente eleito, e acompanhadas atentamente pela sociedade civil, porque o Supremo teve, pouco a pouco, o seu papel político e jurídico de Corte Constitucional realçado. Se a Corte ganhou o respeito que tem hoje, é porque homens públicos como Victor Nunes Leal, Hermes Lima e Evandro Lins e Silva honraram os lugares que ocuparam por conta de seu notável saber e de sua importante coragem em não se curvar ao estado autoritário. Por causa deles, é que hoje podemos ter hoje não um governo de juízes, mas um governo democrático com juízes na defesa da Constituição, como veremos a seguir.

\section{A “Corte Moreira Alves" A JURisprudênCIa defensiva e a JURISDIÇÃO CONSTITUCIONAL NO BRASIL REDEMOCRATIZADO APÓS A CONSTITUIÇÃO 1988}

Seja considerado conservador ou progressista, Moreira Alves nunca foi uma figura unânime. Para a imprensa, o Ministro foi considerado "prócer maior das ideias conservadoras no Supremo Tribunal Federal” (MENDES, 2004, p. 116), possivelmente por ter defendido que juiz não deve falar com a imprensa, salvo nos autos dos processos, ou talvez por ter sido indicado por Presidente da República do regime militar. Há quem diga que houve atraso nas mudanças na Corte que somente teriam começado a ocorrer depois de sua saída. No entanto, há quem entenda que tudo isso não passaria de "uma dessas esquisitices brasileiras que, paradoxalmente, permita que significativos avanços e progressos advenham de inspiração pretensamente conservadoras" (MENDES, 2004, p. 116), justamente porque a contribuição sistemática para o controle de constitucionalidade e para o desenvolvimento da chamada reserva legal proporcional serviu à construção de uma moderna dogmática dos direitos fundamentais. Não queremos entrar na disputa ou tomar posição: não é necessário. A controvérsia, por si só, demonstra a importância de estudar a contribuição do Ministro em foco.

Um civilista na Corte Constitucional. Assim se pode definir, provisoriamente, a judicatura do Ministro José Carlos Moreira Alves no Supremo Tribunal Federal, uma vez que a maior parte de seus livros e artigos versa sobre o direito civil e o direito romano. A principal obra sobre o direito romano no País pertence ao Ministro. Esta já ultrapassou a 14 ${ }^{a}$ edição e vem sendo editada, ampliada e revisada desde 1965 
(volume I) e, em 1996, teve um volume II publicado (ALVES, 2008). Professor dessas cadeiras em universidades públicas e privadas, Moreira Alves era de fato um civilista em uma época em que - por paradoxal que possa parecer a quem já se acostumou à normatividade da Constituição de 1988 - o Código Civil tinha a importância fática análoga a de uma Constituição: as constituições passavam e o Código Civil de 1916 perdurava. O Brasil teve cinco ou seis (se contarmos a EC n. 1, de 1969) Constituições no século XX e apenas um Código Civil. Apenas em 2002 um novo Código Civil foi aprovado.

O Ministro Moreira Alves tinha a exata noção da importância institucional do Supremo Tribunal Federal, ao reconhecê-lo como "grande Corte da Federação" para identificar os seus momentos de crise funcional, como avalanche de processos gerados pela utilização do recurso extraordinário por partes inconformadas com o resultado dos julgamentos nos Tribunais inferiores. Ainda em decorrência disso, pode-se verificar que o Ministro Moreira Alves trabalhou ativamente na Assembleia Nacional Constituinte de 1987, criticando a retirada da função que o Supremo Tribunal Federal desempenhou por mais de noventa anos do seu papel de Tribunal unificador da aplicação do direito federal infraconstitucional. Por isso, nesse momento, não houve uma transformação profunda do Supremo Tribunal Federal em Corte Constitucional exclusiva, tal qual o modelo europeu com mandatos temporários.

É possível organizar em três eixos a jurisprudência da época em que o Ministro Moreira Alves atuou decisivamente no STF que podem até não ser uma completa novidade, mas, no mínimo, ganharam novas luzes: (i) a definição e caracterização de certas formas de controle como processo objetivo, bem como a aplicação de duas técnicas interpretativas, quais sejam, interpretação conforme e o princípio da proporcionalidade; (ii) os efeitos da decisão em cautelar ou da ação em si, se poderiam ser considerados ainda constitucionais apelando ao legislador, bem como se seriam ex tunc, ex nunc, inter partes ou erga omnes; e (iii) o controle da inconstitucionalidade por omissão.

O Ministro José Carlos Moreira Alves foi um dos precursores de temas centrais do controle de constitucionalidade no Brasil. Justamente por isso, começamos com o destaque de sua contribuição para a formação de uma lógica de um processo objetivo, a aplicação dos princípios da interpretação conforme e do princípio da proporcionalidade. São três elementos estruturantes de modo a desempenhar a análise da compatibilidade entre a lei com a Constituição que superam a tradicional lógica do controle do caso concreto de interesses particulares, como teremos a oportunidade de conferir.

Na Representação n. 1.016, julgou-se a (in)constitucionalidade de leis estaduais que desmembraram o Município de Ibirarema, anexando-o ao de Palmital no Estado de São Paulo, sem prévia consulta às populações interessadas. A representação de inconstitucionalidade não foi conhecida, sob o argumento de que as leis eram anteriores à 
Constituição então vigente, de forma que se estava diante de uma hipótese de revogação e não de inconstitucionalidade. Não se admitia o controle de lei revogada, que deveria ser feito no caso concreto. O Ministro Moreira Alves destacou que nesses casos há o controle incidenter tantum que só adquire eficácia erga omnes se o Senado Federal assim desejar. Também enfatizou que a representação tem efeito erga omnes com reflexos sobre o passado, ex tunc, independentemente de o Senado atuar porque se trata de “decisão de conveniência política” pelo interesse superior da preservação do respeito à Constituição, como um instrumento especialíssimo de defesa da ordem jurídica.

Na Ação Rescisória n. 878, um serventuário do $2^{\circ}$ tabelionato de Notas da comarca de Cafelândia pretendia desconstituir o acórdão proferido na Representação n. 665 do Supremo Tribunal Federal que declarou a inconstitucionalidade de um decreto paulista. O Decreto n. 44.794/65 restabeleceu o ofício de registro de imóveis da Comarca de Cafelândia. Como houve a declaração da inconstitucionalidade, o autor perdeu a serventia que tinha optado. O Supremo Tribunal entendeu que o particular não tem legitimidade para intentar ação rescisória. Diversos Ministros, entre os quais Moreira Alves, destacaram que a ação direta de inconstitucionalidade serve para um controle político da Constituição em caráter excepcional, atribuído à Suprema Corte. É ao Supremo que compete decidir sobre os limites da atuação entre os poderes para elaborar uma lei, mas isso significa que esteja exercendo uma forma de prestação jurisdicional a certos sujeitos. Mais uma vez, nota-se o distanciamento da defesa de direitos subjetivos em juízo em relação à defesa da ordem jurídica por meio de um processo objetivo.

Um último caso essencial para definição da representação de inconstitucionalidade como um processo objetivo refere-se, de forma explícita, à Representação n. 1.405/AC. Nela, questionava-se um dispositivo da Constituição do Acre que permitia ao Procurador-Geral do Estado representar ao Tribunal competente sobre a inconstitucionalidade. A dúvida era a possibilidade de impugnar a constitucionalidade de leis estaduais ou municipais por meio de um controle instituído pelo poder constituinte do Estado-membro. Entendeu-se que tal previsão era inconstitucional, porque a legitimidade para propor a representação de inconstitucionalidade pertencia exclusivamente ao Procurador-Geral da República, Chefe do Ministério Público Federal e, ainda que o Estado pudesse instituí-lo, segundo o Supremo, deveria ser respeitada a titularidade desse processo de cunho objetivo. Em seu voto, o Ministro Moreira Alves manifestava-se explicitamente no sentido de diferenciar a intervenção federal da representação de inconstitucionalidade, que se apresenta como "processo objetivo, e, portanto, sem partes, autêntico meio de controle político da Constituição que é deferido em caráter excepcionalíssimo a esta Corte”.

Outro tema importante nesse estágio foi o manejo de algumas técnicas de interpretação constitucional, que são a interpretação conforme e a proporcionalidade, cujos precedentes passamos a resumir a seguir. 
Na Representação n. 948, decidiu-se um caso sobre a Constituição do Estado de Sergipe que acrescentou algumas restrições à concessão de subsídio mensal vitalício, depois de cessada a investidura no cargo de governador do Estado, não previstas no art. 184 da EC n. 1, de 1969. No caso, a Constituição estadual exigia que para ter o referido subsídio seria necessário permanecer por período equivalente a no mínimo metade do mandato e não sofrer suspensão de direitos políticos. O Ministro Moreira Alves conferiu ao artigo da Constituição estadual uma interpretação que considera que a restrição efetuada encontra-se dentro do espírito do texto constitucional federal. Como se pode facilmente perceber, isso não passa de uma interpretação conforme à Constituição.

Como dito acima, outra técnica difundida no período foi o uso da proporcionalidade ou razoabilidade.

Na Representação n. 1.077/RJ, por exemplo, julgou-se que um percentual excessivo para a taxa judiciária representaria um obstáculo para a obtenção da prestação jurisdicional, o que seria inconstitucional por violar a garantia do acesso à justiça. O Ministro Moreira Alves destacou em seu voto que a taxa judiciária, embora alguns tenham chegado a defender que teria a natureza de imposto, possui não só o nome, mas também a natureza jurídica de taxa. Como tal, deve guardar uma equivalência razoável entre a alíquota e o serviço prestado pelo Judiciário. Ainda que esse limite seja variável e relativo, deve haver alguma proporção com a contraprestação. Por essa razão, uma alíquota com custo invariável para causas acima de determinado valor revela-se inconstitucional, seja pelo excesso de valores dessa cobrança, seja por transformá-la em um imposto.

Quanto aos efeitos da decisão no controle de constitucionalidade, três temas podem ser considerados as contribuições centrais do Ministro Moreira Alves: (i) a eficácia erga omnes, ou seja, oponível contra todos; (ii) o efeito em regra ex tunc da decisão ou seja, retroativos; e (iii) a possibilidade de cautelar em ADI com efeitos, em regra, desse momento para frente, ex nunc.

No Processo Administrativo n. 4.477-72, a decisão foi em consonância do parecer de 11 de novembro de 1975, da lavra do Ministro Moreira Alves, no qual se defendeu que a comunicação do Senador é possível e necessária para aplicar o efeito erga omnes nos casos de declaração incidental de inconstitucionalidade. Quando a declaração de inconstitucionalidade em tese decorrer de ação direta, não há falar em comunicação ao Senado, justamente porque, nessa hipótese, transitando em julgado o acórdão do Supremo Tribunal Federal, ele já possui efeitos erga omnes (MENDES, 2004, p. 178-183). Essa questão representa um passo muito importante na jurisdição constitucional, conferindo força à ação direito de inconstitucionalidade no sentido de poder derrubar efetivamente as leis aprovadas pelo Parlamento.

Na Representação n. 933/RJ, Moreira Alves, então Procurador-Geral da República, requereu cautelar para suspender a eficácia do ato normativo impugnado. O Ministro 
Thompson Flores, relator da Representação, entendeu que o STF tinha competência para tomar medidas para garantir a eficácia ulterior da decisão, nos termos do requerimento de Moreira Alves. A controvérsia, porém, só ficou superada definitivamente com o advento da Emenda Constitucional n. 7, de 1977, à Constituição de 1967 (na redação da EC n. 1, de 1969) que consagrou a possibilidade de o Procurador-Geral de República oferecer o pedido de medida cautelar de forma expressa. Na Constituição de 1988, o art. 102, § 3º, também positivou o tema de forma expressa.

Na Representação n. 1.391/QO, foram discutidos quais seriam os efeitos da liminar em representação de inconstitucionalidade, mais precisamente, se seriam os mesmos da representação (ex tunc, retroativos) ou se valeriam do momento de concessão da medida cautelar em diante (ex nunc, desde então). No caso, a dúvida decorria da impugnação da inconstitucionalidade de lei do Estado do Ceará que concedia algumas gratificações a servidores e magistrados. Com intuito de resguardar o tesouro estadual de difícil e incerta reparação, a liminar foi concedida, nos termos do voto do relator, Célio Borja. Coube, porém, ao Ministro Moreira Alves esclarecer que, na cautelar, não se está declarando a inconstitucionalidade com efeitos retroativos. Elucidou, ainda, que, ao se pleitear a liminar, não se pretende a devolução de todas as parcelas já recebidas. A intenção é resguardar o interesse público a partir da concessão da liminar, ou seja, com efeitos ex nunc. O Tribunal, então, concluiu que a eficácia da medida cautelar deve valer do momento da concessão em diante, como dito, ex nunc.

Um tema em especial no período demonstra a forma comedida com a qual o Supremo da época via os limites da atuação do Judiciário diante da separação de poderes: o controle das omissões inconstitucionais. A impossibilidade de a Corte atuar como legislador positivo, devendo se circunscrever o controle a uma categoria que passou a habitar o STF desde então, a do "legislador negativo" foi uma marca registrada da Corte Moreira Alves. São justamente os casos dos Mandados de Injunção n. 107 e 232, que tratam da omissão inconstitucional que tais temas ganham fama como traço distintivo da jurisprudência do período estudado.

No Mandado de Injunção n. 107, o cidadão José Emídio Teixeira Lima o impetrou com objetivo de suspender o seu licenciamento do serviço ativo do Exército por contar com mais de nove anos de serviço na condição de oficial. A alegação era a omissão do Presidente da República, a quem caberia a iniciativa do projeto em relação à norma do art. $42, \S 9^{\circ}$. O dispositivo prevê que a lei disporá sobre os limites de idade, a estabilidade e outras disposições de transferência servidor militar para inatividade. O caso suscitou duas questões de ordem basicamente: (i) se a norma do art. 5 , LXXI, da Constituição de 1988 que prevê o mandado de injunção é autoaplicável sem uma lei que regulamente o seu procedimento; e (ii) a natureza jurídica do mandado de injunção e os efeitos da decisão. Por unanimidade e nos termos do voto 
do relator, o Ministro Moreira Alves entendeu que a norma era, sim, autoaplicável, sendo cabível aplicar por analogia a Lei do Mandado de Segurança, ou seja, o mandado de injunção poderia ser utilizado. Quanto à segunda, entendeu-se que sua natureza era mandamental, o que significa que visa obter do Poder Judiciário a declaração de inconstitucionalidade dessa omissão pela mora do Poder, órgão, entidade ou autoridade de que ela dependa. Defendeu-se que não adotar a natureza constitutiva para ação, não implica considerá-la inapta a produzir efeitos. O efeito produzido é o reconhecimento da mora e a possibilidade de suspender processos judiciais e administrativos que possam causar danos ao impetrante se não fosse reconhecida a omissão inconstitucional.

No Mandado de Injunção n. 232, por sua vez, o Centro de Cultura Professor Luiz Freire impetrou o referido remédio constitucional, sob o fundamento da omissão inconstitucional decorrente do não cumprimento da obrigação de legislar presente no art. $195, \S 7^{\circ}$, que concede a entidades beneficentes de assistência social imunidade da contribuição para seguridade social, caso sejam atendidas certas exigências em lei. Lei essa que ainda não havia sido aprovada. Reforçando a omissão inconstitucional, o art. 59 dos ADCT previa que em seis meses da promulgação da Constituição deveriam ser apresentados os projetos de lei sobre a seguridade social. O mandado de injunção foi conhecido em parte para declarar a mora do Congresso Nacional e adotar a providência dentro de seis meses de modo que tais entidades possam gozar da referida imunidade. Assim, o Supremo, nos termos do voto do Ministro Moreira Alves, decidiu que esse direito não nasce diretamente da norma constitucional, sendo necessária a lei, prevendo os requisitos para desfrutar da referida imunidade.

Como se pode observar pela jurisprudência do período entre 1975 e 2003, o Supremo Tribunal Federal, em geral, e o Ministro Moreira Alves, em particular, foram experimentando as bases do que veio a ser o controle de constitucionalidade no Brasil, sob o formato de um processo objetivo, compreendido tradicionalmente como um processo sem partes ou interesses subjetivos. É verdade que essa ideia hoje poderia ser problematizada a partir da categoria "representação argumentativa" (ALEXY, 2007, p. 53) ou pela necessidade de a Corte contemplar procedimental e argumentativamente os múltiplos interesses, presentes em uma sociedade democrática e plural. Ainda é preciso amadurecer esse debate para saber até que ponto é possível estender o conceito de partes não com uma referibilidade individual, mas a partir desse grupo. Certo é, porém, que a construção do controle como processo objetivo está nas raízes de sua construção. Ainda que nada seja para sempre, a jurisprudência da Corte Moreira Alves ainda se mostra presente na jurisdição constitucional no Brasil ou, pelo menos, no que ela pode ou não vir a ser. Muito do que foi decidido se transformou em dispositivo legal, súmula ou jurisprudência dominante. Havia alguns dispositivos constitucionais com diretrizes para o controle, mas a legislação a esse respeito só veio em 1999 com as Leis n. 9.868 e n. 9882 e, 
em relação à ADI por omissão, apenas em 2009 com a Lei n. 12.063 que alterou a redação da Lei n. 9.868/99.

O cenário atual é outro: maior ativismo e maior judicialização da política e da vida. E é desse cenário que trataremos a seguir.

\section{A “Corte Gilmar":}

\section{O ATIVISMO JUDICIAL E A JUDICIALIZAÇÃO DA VIDA E DA POLÍTICA}

O Ministro Gilmar Ferreira Mendes possui uma extensa carreira acadêmica e prática, que o levou a elaborar reflexões importantes sobre o controle de constitucionalidade. Gilmar Ferreira Mendes obteve graduação em direito na Universidade de Brasília em 1978 e o Mestrado na mesma instituição em 1987 com tema "Controle de Constitucionalidade: Aspectos Jurídicos e Políticos”, sob orientação do Ministro Moreira Alves. Obteve, ainda, grau de Doutor com a tese $O$ controle abstrato de normas perante a Corte Constitucional Alemã e perante o Supremo Tribunal Federal, pela Westfälische Wilhelms-Universität Münster, RFA. O Ministro se dedicou à docência desde 1978 em diversas instituições, em especial na Universidade Brasília. Foi um dos fundadores do Instituto Brasiliense de Direito Público, em 1998. Atualmente, exerce o cargo professor Adjunto de Direito Constitucional de graduação e pós-graduação da Faculdade de Direito da Universidade de Brasília. Do ponto de vista acadêmico, tornou-se referência obrigatória no tema controle de constitucionalidade em razão dos diversos e profundos livros e artigos que publicou ao longo de sua trajetória. Contribuiu, ainda, para o enriquecimento do debate do direito constitucional ao traduzir obras de juristas alemães relevantes no pós-guerra, como Peter Häberle e Konrad Hesse. Em razão de sua forte ligação com o mundo jurídico alemão, sempre esteve atento às relevantes discussões doutrinárias por lá, adaptando-as à realidade brasileira, o que se comprova também pela leitura dos seus votos, por exemplo.

Quanto à sua vida profissional, foi Procurador da República com atuação em processos do STF de 1985 a 1988. Foi Consultor Jurídico da Secretaria Geral da Presidência da República entre 1991 e 1992 e Assessor Técnico na Relatoria da Revisão Constitucional na Câmara dos Deputados nos dois anos seguintes. Tornou-se Subchefe para Assuntos Jurídicos da Casa Civil de 1996 até 2000 e Advogado-Geral da União entre 2000 e 2002. Em seguida, o Presidente Fernando Henrique Cardoso indicou Gilmar para Ministro do Supremo Tribunal Federal. Entre 23 de abril de 2008 e 22 de abril de 2010 exerceu a função de Presidente do STF, período que será estudado.

Diversos casos e viradas jurisprudenciais são importantes para compreender a “Corte Gilmar Mendes". Igualmente diversas são as formas de apresentá-los, mas se reduziu o tema à seguinte sequencia didática a partir dos instrumentos para acessar a corte constitucional: (i) ADI; (i) ADC; (iii) ADPF; (iv) ADI por omissão e mandado e 
injunção; (v) recurso extraordinário, repercussão geral e revisão de tese; (vi) súmula vinculante; e (vii) audiências públicas.

Vejamos, primeiramente, uma ação direta de inconstitucionalidade que ilustra as feições assumidas pela jurisdição constitucional na análise de temas significativos para os cidadãos brasileiros.

A Ação Direta de Inconstitucionalidade n. 3.510 foi proposta pelo PGR contra o art. $5^{\circ}$ da Lei de Biossegurança. Nele, o Ministro Gilmar Mendes afirma que a Constituição de 1988 adota tanto o princípio responsabilidade quanto o princípio esperança, assegurando que nossa evolução constitucional ocorra entre a razão e a emoção. Salienta que a Lei de Biossegurança não regula a pesquisa com a prudência necessária. A lei não instituiu um imprescindível Comitê Central de Ética, além de ser omisso quanto o uso subsidiário da pesquisa diante de meios menos gravosos. Quando a lei deixa de prever essa possibilidade, afronta o princípio da proporcionalidade. Portanto, deve-se conferir ao art. $5^{\circ}$ uma interpretação conforme a Constituição para prever tal Comitê. Ao final do julgamento, no entanto, o Ministro restou vencido, porque, por maioria, a ação foi declarada improcedente, não sendo necessária a criação de um Comitê Central.

Estudemos agora algumas ações declaratórias de constitucionalidade de caráter relevante.

Na ADC n. 12-MC, a Associação dos Magistrados do Brasil buscava o reconhecimento da constitucionalidade da Resolução n. 7/2005 do CNJ que proibia o nepotismo. O voto do Ministro Gilmar Mendes, quando a Constituição confere ao CNJ a competência de fiscalizar a atuação administrativa do Poder Judiciário e fazer cumprir o art. 37, implicitamente concede os poderes necessários para o exercício e fiscalização dos atos administrativos do Poder Judiciário que violem tais princípios. Não há dúvida de que os atos que impliquem a prática do nepotismo ofendem diretamente os princípios da moralidade e da impessoalidade. Ao final, vota pelo deferimento da cautelar para paralisar o julgamento, em instâncias inferiores, dos processos que envolvem a aplicação da lei ou do ato normativo objeto da ação, até o seu julgamento definitivo. O Supremo, por maioria deferiu a liminar. No mérito, a ADC n. 12 manteve a liminar e o Ministro Gilmar Mendes apenas reafirmou o voto que já havia proferido na cautelar.

Outra importante e recente Ação Declaratória de Constitucionalidade é a de n. 16. Questionava-se a responsabilidade subsidiária do Estado na terceirização em caso de inadimplemento das obrigações trabalhistas pelo empregador. O STF desconstruiu uma parte substancial da jurisprudência de mais de uma década do TST (Súmula n. 331) ao reavaliar a questão da responsabilidade subsidiária do Estado, nos casos de terceirização de serviços. A maioria dos ministros entendeu que a mera inadimplência da empresa contratada não possui o condão de, por si só, transferir à Administração Pública a responsabilidade pelos pagamentos dos encargos trabalhistas. 
Isso não significa que eventual omissão da Administração Pública na obrigação de fiscalizar as obrigações do contratado não pode vir a gerar essa responsabilidade. Ao contrário, para haver a responsabilização subsidiária, faz-se necessário comprovar caso a caso a falha ou falta de fiscalização pelo órgão público competente. Por maioria, o Supremo reconheceu a constitucionalidade do art. $71, \S 1^{\circ}$, e, mitigando a Súmula n. 331 do TST, exigiu que fosse comprovada falha/falta de fiscalização pelo órgão público para a sua responsabilização subsidiária da Administração Pública direta ou indireta (tomadora do serviço) por inadimplemento das obrigações trabalhistas pelo empregador.

Vejamos agora algumas arguições de descumprimento fundamental do período.

$\mathrm{Na}$ ADPF n. 46, questionou-se o monopólio dos Correios sustentado pela Lei n. 6.538/78 com base na livre-iniciativa. O Tribunal, por maioria, votou a favor da recepção da lei, uma vez que os correios desempenham um serviço público, devendo ser prestado exclusivamente pela União, quando envolver a distribuição de cartas pessoais e comerciais, cartões-postais, malotes (correspondência agrupada) e emissão de selos. Tudo que não encontrar abrigo nas espécies citadas é livre à iniciativa privada. O Ministro Gilmar Mendes votou no sentido de que a entrega de cartas pessoais deveria ficar sobre o monopólio da ECT, enquanto as demais formas de correspondência seriam abertas ao mercado. Por maioria, o Supremo julgou a ação procedente.

Outra importante ADPF julgada nesse período foi a de n. 130, manejada pelo PDT contra a Lei n. 5.250/67 (Lei de Imprensa aprovada na época da ditadura), cujo objetivo era ver declarado que alguns dispositivos não foram recepcionados pela Carta de 1988 e outros carecem de interpretação conforme com ela compatível. O voto do Ministro Gilmar Mendes afirmou a compatibilidade da liberdade de imprensa com uma lei específica reguladora, porque Constituinte de 1988 não concebeu a liberdade de expressão como direito absoluto. A liberdade de informação deve ser exercida de modo compatível com o direito à imagem, honra e vida privada. Destacou, porém, que a atual Lei de Imprensa está impregnada de um espírito autoritário e os seus dispositivos, por este motivo, devem ser afastados por juízes / tribunais no caso concreto. Logo, o que resta e é aplicado pela Lei de Imprensa apenas resguarda o cidadão, empresas e jornalistas, sem ameaçar direitos fundamentais. Esta lei protege o indivíduo contra o abuso do poder da imprensa ao garantir o direito de resposta (garantia fundamental) que necessita de lei infraconstitucional para eventual exercício. Ao final, votou pela declaração de não recepção parcial da Lei n. 5.250/67, mantendo os arts. 29 a 36 referentes ao direito de resposta que hoje está em discussão a possibilidade de regulamentação legislativa. O Supremo, por maioria, julgou a ação procedente e todos os dispositivos da Lei de Imprensa foram considerados não recepcionados.

Vejamos agora a jurisprudência do período em relação ao controle da inconstitucionalidade por omissão. 
Na ADI n. 240, ajuizada pelo PT contra a Lei n. 7.619/2000, questionava-se a criação do Município "Luís Eduardo Magalhães", por inobservância dos requisitos constitucionais, notadamente o art. $18, \S 4^{\circ}$, da Constituição, que exigia disciplina por lei complementar. O Ministro Gilmar Mendes votou pela declaração de inconstitucionalidade, mas destacou que isso traria graves repercussões de ordem política, econômica e social. Julgar apenas improcedente não seria a solução mais adequada. A nulidade da lei inconstitucional foi objeto de ponderação. Embora continue a ser a regra, sua incidência sofreu uma modulação em nome da segurança jurídica e dos impactos sociais desencadeados. O Ministro Gilmar votou no sentido de declarar a inconstitucionalidade sem a pronúncia de nulidade da lei impugnada, mantendo sua vigência pelo prazo de 24 meses, ou seja, realiza a modulação de efeitos temporais, considerando essa "força normativa dos fatos". O Supremo, por unanimidade e após a mudança dos votos de alguns ministros, julgou a ação procedente, embora, por maioria, os ministros votaram a não pronunciar nulidade do ato impugnado, com efeitos pro futuro. O que ocorreu, em 2008, porém, foi que a lei não foi editada e o Congresso Nacional aprovou a Emenda n. 57 à Constituição para convalidar os municípios, como o de Luís Eduardo Magalhães que foram criados de forma inconstitucional até 2006 .

Talvez, o caso que gerou maior discussão doutrinária tenha sido o Mandado de Injunção n. 708. Impetrado pelo Sindicato dos Trabalhadores em Educação do Município de João Pessoa (SINTEM) em face do Congresso Nacional, o remédio almejava suprir a omissão legislativa federal. Em razão da paralisação realizada por professores, a administração pública municipal requereu a declaração de ilegalidade da greve ao TJPB tendo sido o pedido deferido. O voto do Ministro Gilmar Mendes adotou o que ele mesmo chamou de uma solução "normativa concretizadora" em prol de direitos constitucionalmente assegurados. Se até então o Supremo apenas se limitava a constatar a inconstitucionalidade da omissão e a determinar que o legislador tomasse as providências requeridas, a partir daí, passou a aplicar analogicamente a Lei n. 7.783/89, que cuida da greve do setor privado, para os servidores, enquanto a omissão não for regulamentada por lei específica. Por maioria, o Supremo conheceu o mandado de injunção para solucionar a omissão legislativa do art. 37, VII, da Constituição.

Analisaremos agora as contribuições do Ministro em questão no que diz respeito ao recurso extraordinário e institutos acessórios, como repercussão geral e revisão de tese.

A Emenda Constitucional n. 45 introduziu a repercussão geral como requisito de admissibilidade no recurso extraordinário. O STF passou a selecionar mais rigorosamente os casos a partir da presença simultânea dos critérios: (a) relevância ("considerada a existência, ou não, de questões relevantes do ponto de vista econômico, político, social ou jurídico”); e (b) transcendência (“que ultrapassem os interesses 
subjetivos da causa"). Dessa análise, o STF edita o enunciado de repercussão geral, que valerá para todos os casos análogos suspensos e os futuros. Fato esse que levou a uma diminuição drástica do número de recursos, bem como a uma progressiva mudança no perfil deste, que cada vez mais se tornam casos pretextos para discutir temas.

A princípio, o reconhecimento ou rejeição da repercussão geral é irrecorrível. Contudo, questiona-se a possibilidade de, diante da superveniência de novos fatos ou argumentos jurídicos, uma questão sem repercussão geral considerada em um caso, posteriormente possa ser dotada de repercussão geral. O primeiro caso em que se aplicou o procedimento denominado revisão de tese foi publicado no Informativo n. 605 do STF. Reviu-se a tese firmada em um precedente anterior, que negou repercussão geral a uma decisão da Turma Recursal dos Juizados Especiais Federais do Rio de Janeiro, porque posteriormente a decisão que rejeitou repercussão geral o TRF da $4^{\text {a }}$ Região declarou a inconstitucionalidade sem redução do texto do art. 12 da Lei n. 7.713/88 (que determinava a incidência da alíquota do imposto de renda sobre os valores recebidos de forma cumulativa), atingindo um número maior de contribuintes. Com base na necessidade de isonomia e na mudança superveniente das premissas fáticas, a matéria passou a ter repercussão geral reconhecida pelo STF.

Instrumento já mencionado neste trabalho, as súmulas adquirem feições inovadoras após os efeitos vinculantes introduzidos pela EC n. 45/2004 e, em especial, sob a presidência de Gilmar Mendes.

De fato, durante o período em que Ministro Gilmar Mendes esteve na Presidência do STF, foi o crescimento do número de súmulas vinculantes editadas. Vejamos alguns exemplos das propostas pelo Ministro Gilmar Mendes. A Súmula Vinculante n. 5 prevê que a falta de defesa técnica por advogado no processo administrativo disciplinar não ofende à Constituição. A Súmula Vinculante n. 7 prevê que a norma do $\S 3^{\circ}$ do art. 192 da Constituição, revogada pela Emenda Constitucional n. $40 / 2003$, que limitava a taxa de juros reais a $12 \%$ ao ano, tinha sua aplicação condicionada à edição de lei complementar.

Outras súmulas vinculantes do período que suscitaram muita discussão foram a Súmula n. 11, referente ao uso das algemas, e a n. 25, que cuidou da prisão civil do depositário infiel. A Súmula Vinculante n. 11, proposta pelo Ministro Cezar Peluso, prevê que só é lícito o uso de algemas em casos de resistência e de fundado receio de fuga ou de perigo à integridade física própria ou alheia, por parte do preso ou de terceiros, justificada a excepcionalidade por escrito, sob pena de responsabilidade disciplinar, civil e penal do agente ou da autoridade e de nulidade da prisão ou do ato processual a que se refere, sem prejuízo da responsabilidade civil do Estado. Em um dos precedentes que deu origem ao caso, o Ministro Gilmar Mendes salientou que seria uma tortura psíquica ou uma injusta vexação que aplica a sanção não prevista, o que viola a dignidade da pessoa humana. O uso das algemas só deve ocorrer em casos excepcionais. Salienta que esse deveria ser o posicionamento do Tribunal não 
apenas para os casos do Júri. Já a Súmula Vinculante n. 25 afirma que é ilícita a prisão civil de depositário infiel, qualquer que seja a modalidade do depósito. Em um dos precedentes que originou o seu entendimento, o Ministro Gilmar Mendes reconheceu que os tratados de direitos humanos têm significado ímpar. Com a assinatura do Pacto Internacional dos Direitos Civis e Políticos e a Convenção Americana sobre Direitos Humanos, não há mais base legal para prisão civil do depositário infiel, pois o caráter especial desses diplomas internacionais sobre direitos humanos lhes reserva lugar específico no ordenamento jurídico, estando abaixo da Constituição, porém acima da legislação interna. Tem status normativo supralegal dos tratados internacionais de direitos humanos. Houve também um maior intercâmbio com precedentes de outros tribunais constitucionais e uma maior, ainda que tímida, abertura para o direito internacional.

Também foi claramente perceptível o crescimento em importância das audiências públicas na prática do Supremo Tribunal Federal. Nos últimos cinco anos, houve uma maior atenção do Supremo no tocante à realização de audiências públicas, com a pretensão de construir uma sociedade aberta dos intérpretes da Constituição. Estas vêm sendo utilizadas em casos e temas de grande relevância social ou casos de especial complexidade técnica. Um exemplo foi a audiência pública foi promovida pelo STF, cujo intuito era debater a política de cotas como meio de ingresso ao ensino superior. Participaram grupos contrários e favoráveis a esta política pública, trazendo elementos importantes para auxiliar os Ministros quanto ao tema. O grupo contrário afirmou que a cota exclusivamente racial seria inconstitucional, pois a utilização de critérios étnicos contribuiria para o racismo, defendendo, porém, as cotas com base em critérios econômicos. Já os favoráveis defendem se tratar de políticas públicas tipicamente inclusivas e que almejam a diminuição das desigualdades raciais e sociais. É um meio eficiente de real inclusão.

Apresentamos os principais julgados Supremo Tribunal Federal relacionados ao período próximo aos anos de 2008 a 2010. A data não foi escolhida de forma aleatória: os anos de 2008 a 2010 foram aqueles sob a Presidência do Ministro Gilmar Mendes. O momento representou para o Supremo Tribunal Federal uma confluência entre o civil law e o sistema da common law. Caminhamos em direção a uma jurisprudência que assume o papel não apenas de dizer o direito, mas também o de criá-lo, de concretizá-lo. Foram, sem dúvida, anos de judicialização da vida e da política, permeados por um ativismo judicial mais acentuado, o que não significa que o Ministro Gilmar Mendes possa ser considerado sem maiores reflexões e sempre ativista. Não desejemos fazer uma digressão para explicar o que é o ativismo, já que existem pesquisas primorosas sobre o tema (MIRANDA NETTO, 2012, p. 87). Nossa conclusão quanto ao período se limita a dizer que se constata um maior ativismo no sentido do senso comum, quando comparamos esse período com o anterior: a Corte Moreira Alves. Contribuíram para isso os instrumentos processuais disponíveis, como 
a reclamação, a repercussão geral no recurso extraordinário, o crescimento do número de súmula vinculante e o novo perfil do mandado de injunção. No entanto, a principal mudança foi a de mentalidade: a Constituição dotada força normativa, a corte constitucional como espaço aberto à sociedade civil em audiências públicas e o Judiciário como uma importante instituição contramajoritária.

\section{CONCLUSÕES}

Ao início do trabalho que agora se encerra, propusemos realizar uma análise do Supremo Tribunal Federal por meio de três recortes históricos, centralizados nas figuras de três de seus Ministros: Victor Nunes Leal, José Carlos Moreira Alves e Gilmar Ferreira Mendes. Por certo, não apenas os ministros elencados, mas diversos outros que passaram pela Corte foram fundamentais para construção da jurisdição constitucional que se apresenta hoje no Brasil. O propósito do texto, porém, pretendeu abordar o tema de uma forma que não é comum na literatura jurídica brasileira, organizando estudos jurisprudenciais por meio de um critério que toma como referencial a figura de um ministro com o intuito de ser capaz sintetizar muitos anos de jurisdição constitucional em poucas páginas. Trata-se em uma espécie de metonímia que através da parte pretende traçar um perfil do todo.

Verificamos que a "Corte Victor Nunes Leal" foi marcada pela dificuldade no exercício da função jurisdicional de guarda da Constituição pelo Supremo, em razão da hipertrofia institucional do Executivo que chegou até mesmo a aposentar compulsoriamente magistrados contrários ao regime, dentre os quais o próprio Victor Nunes. Não obstante, este Ministro, ainda que por muitas vezes votasse vencido contribuiu ao enfrentar as tentativas do regime vigente de afastar determinados atos do Executivo da apreciação jurisdicional de compatibilidade com o texto constitucional, reiterando por diversas vezes sua posição acerca da natureza infraconstitucional dos Atos Institucionais e a subordinação destes aos ditames da Constituição vigente. Além disso, do ponto de vista da jurisdição constitucional, o período foi marcado principalmente pela contribuição de Victor Nunes Leal com a criação da súmula de jurisprudência dominante, relevante instrumento de trabalho que representou um pontapé inicial em direção a métodos capazes de dotar as decisões do Tribunal de maior isonomia, celeridade e racionalização.

Vencidos os obstáculos políticos para que a jurisdição constitucional fosse alçada à condição de instrumento efetivo no cenário brasileiro, restariam às gerações seguintes remover os obstáculos teóricos e práticos para a utilização dos novos instrumentos de controle de constitucionalidade postos sob a guarda do Supremo pela Constituição de 1988. Nesse sentido, a "Corte Moreira Alves" foi responsável por consagrar a lógica de um processo objetivo no controle concentrado de constitucionalidade, bem como diversas técnicas de interpretação adequadas ao exercício da 
função de guardião da Constituição. Tais inovações, contudo, foram acompanhadas de considerável parcimônia e cautela em seu manejo, em apreço a uma visão conservadora da separação de poderes na época, que pode ser denominada de "jurisdição defensiva”.

Por fim, a "Corte Gilmar Mendes" evidenciou um terceiro momento histórico, a partir do qual o Judiciário definitivamente foi alçado à condição de protagonista no cenário político brasileiro, proferindo decisões que ousaram ir um pouco além das tendências autocontidas da "Corte Moreira Alves" e consolidando-se como importante instância contramajoritária, na qual acabam sendo discutidos os maiores dilemas institucionais da nação. Já consolidadas as técnicas de interpretação e aspectos processuais mais relevantes dos instrumentos de controle concentrado, o Supremo passa a agir de forma mais ativista, como, por exemplo, no caso da inconstitucionalidade por omissão, tema em relação ao qual a mudança de entendimento foi considerável em relação ao momento anterior.

Não é o objetivo desta breve análise fazer um juízo de valor sobre qualidades e defeitos de uma ou outra época ou das virtudes e pecados desse ou daquele Ministro, apontando um período como "melhor" ou "pior" em relação aos outros com os quais foi comparado. O objetivo deste trabalho foi justamente demonstrar que é possível identificar marcos temporais com características próprias a partir de personalidades emblemáticas do período, o que permite entender melhor o papel contemporâneo da jurisdição constitucional no Brasil não apenas a partir dos textos constitucionais e legais, mas também dos homens que ajudaram a (re)inventar a jurisdição constitucional brasileira. Afinal, não há como compreender o presente ou prever tendências para o futuro sem um cuidadoso olhar para o passado e o gradual processo de construção das instituições.

: ARTIGO APROVADO (15/05/2013) : RECEBIDO EM 30/07/2012

ALEXY, Robert. Direitos fundamentais no Estado constitucional democrático: para a relação entre direitos do homem, direitos fundamentais, democracia e jurisdição constitucional. Constitucionalismo discursivo. Porto Alegre: Livraria do Advogado, 2007.

ALVES, José Carlos Moreira. Direito Romano. 14. ed. rev., corrig. e aum. Rio de Janeiro: Forense, 2008. . Carta não autoriza STF a criar norma, diz Moreira Alves. Disponível em: <www.iabnacional.org.br>. Acesso em: 2 fev. 2012. 
AMARAL Júnior, José Levi Mello do. É possível identificar uma Corte Gilmar Mendes. Consultor Jurídico, de 23 de abril de 2010. Disponível em: <http://www.eagora.org.br/arquivo/e-possivel-identificar-uma-cortegilmar-mendes>. Acesso em: 23 abr. 2010.

BARROSO, Luís Roberto. A americanização do direito constitucional e seus paradoxos: teoria e jurisprudência constitucional no mundo contemporâneo. In: SARMENTO, Daniel (Org.). Filosofia e teoria constitucional contemporânea. Rio de Janeiro: Lumen Juris, 2009.

O direito constitucional e a efetividade de suas normas: limites e possibilidades da Constituição brasileira.

9. ed. Rio de Janeiro-São Paulo: Renovar, 2008.

Retrospectiva 2011: um ano para não esquecer. Disponível em:

<http://www.luisrobertobarroso.com.br/wp-content/uploads/2012/01/Retrospectiva-2011_31dez11.pdf> Acesso em: 15 jan. 2012.

Interpretação e aplicação da Constituição. 7. ed. São Paulo: Saraiva, 2009.

BASILE, Juliano. Entrevista Moreira Alves - O STF é uma corte abastada da realidade política, diz Moreira

Alves. Valor Econômico, de 24 de agosto de 2011. Disponível em: <www.osconstitucionalistas.com.br>. Acesso em: 10 jan. 2012.

DORE FERNANDES, Eric Baracho. O legado deVictor Nunes Leal: defesa e construção de uma Corte Suprema democrática. Monografia vencedora do I Prêmio Victor Nunes Leal. Brasília: 2010. Disponível em:

<http://www.ivnl.com.br/download/monografia_eric_baracho.pdf>. Acesso em: 10 jan. 2012.

. A contribuição do Ministro Victor Nunes Leal na construção de uma Corte Suprema democrática.

In: PASSOS DE FREITAS, Vladmir (Org.). Juízes e Judiciário: histórias, casos, vidas. Curitiba: Edição por Demanda, 2012, p. 221-229, v. 1.

; LEGALE FERREIRA, Siddharta. Repercussão geral no recurso extraordinário: recorrendo do irrecorrível?. II Seminário do LAFEP - Laboratório Fluminense de Estudos Processuais (Anais). Niterói, 2010, p. 10-20. DUARTE, Fernanda; GODINHO, Marcelo. Notas sobre a Suprema Corte Norte-americana. Revista SJRJ n. 20, 2007, p. 51-59. Disponível em: <http://www.ajuferjes.org.br/PDF/010artigo_02.pdf>. Acesso em: 10 fev. 2012.

HÄBERLE, Peter. Hermenêutica constitucional - a sociedade aberta dos intérpretes da constituição: contribuição para interpretação pluralista e procedimental da Constituição. Tradução Gilmar Ferreira Mendes. Porto Alegre: Sergio Antonio Fabris Editor, 1997 (reimpressão 2002).

HESSE, Konrad. A força normativa da constituição. Tradução Gilmar Ferreira Mendes. Porto Alegre: Sergio Antonio Fabris Editor, 1991.

LEAL, Caio Freire; DORE FERNANDES, Eric Baracho; SOUZA, Kelly Ribeiro Felix. Parâmetros de admissibilidade do recurso extraordinário: a repercussão geral na visão do STF. IV Seminário do LAFEP Laboratório Fluminense de Estudos Processuais. Anais do IV Seminário do LAFEP. Niterói, 2011, p. 23-35.

LEAL, Victor Nunes. Passado e futuro da "Súmula do STF". Revista dos Tribunais, v. 70, n. 553. São Paulo: Revista dos Tribunais, p. 287-299, 1981.

. Coronelismo, enxada e voto: O município e o regime representativo. Rio de Janeiro: Edição Revista Forense, 1948.

LEGALE FERREIRA, Siddharta; MACEDO, Marco Antonio Ferreira. A Corte Moreira Alves (1975-2003): a judicatura de um civilista no STF e o controle de constitucionalidade. Observatório de jurisdição Constitucional. Disponível em: <http://ojs.idp.edu.br/index.php/observatorio/article/viewFile/745/538>. Acesso em: 26 out. 2012.

; MIRANDA NETTO, Fernando Gama de; BASTOS, Thiago Guerreiro. Actuación del Supremo Tribunal Federal brasileño bajo la Presidencia del Ministro Gilmar Ferreira Mendes (2008-2010). In: CANOSA, Eduardo Andrés Velandia (Org.). Derecho procesal constitucional. Bogotá: VC Editorial, 2012, p. 346-354, v. III. ; OLIVEIRA, Elisa C.; SINCLAIR, Allan; ROMANO, Marcus Vinicius Bacellar; VERÍSSIMO, Rachel; LEAL, Caio. O ano do direito público em 2009. Revista de Direito dos Monitores, n. 6, 2009, p. 128-170. Disponível em: <http://www.uff.br/rdm/revistas/rdm_ano2_ed6.pdf>. Acesso em: 26 out. 2012. .; SENNA, Naira Gomes Guaranho; BACCHI, Rodolpho Cézar Aquilino; FERNANDES, Eric Dore Baracho Fernandes. O ano do direito público em 2010: Quando a Corte Constitucional não dá a última palavra. Revista de Direito dos Monitores, n. 9, 2010, p. 149-176. Disponível em:

<http://www.uff.br/rdm/revistas/rdm_ano3_ed9.pdf>. Acesso em: 26 out. 2012.

LEITE, Glauco Salomão. Súmula vinculante e jurisdição constitucional brasileira. Rio de Janeiro: Forense, 2007. MARMELSTEIN, George. Os direitos fundamentais e o Supremo Tribunal Federal. Disponível em:

<www.georgemlima.xpg.com.br/stf.ppt>. Acesso em: 26 out. 2012.

MENDES, Gilmar Mendes. Moreira Alves e o controle de constitucionalidade no Brasil. São Paulo: Saraiva, 2004. . Jurisdição constitucional: o controle abstrato de normas no Brasil e na Alemanha. 3. ed. São Paulo: Saraiva, 1999. 
Estado de direito e jurisdição constitucional (2002-2010). São Paulo: Saraiva, 2011.

MIRANDA NETTO, Fernando Gama. O ativismo judicial nas decisões do Supremo Tribunal Federal. In: SOUZA, Marcia Cristina Xavier de; RODRIGUES, Walter dos Santos (Coords.). O novo Código de Processo Civil. Rio de Janeiro: Elsevier, p. 87-99, 2012.

; CAMARGO, Margarida Maria Lacombe. Representação argumentativa: fator retórico ou mecanismo de legitimação do Supremo Tribunal Federal? Trabalho publicado nos Anais do XIX do CONPEDI, realizado em Fortaleza, 2010. Disponível em:

<http://www.conpedi.org.br/manaus/arquivos/anais/fortaleza/3589.pdf>. Acesso em: 15 jan. 2012. MOSQUEIRA, Pedro Augusto de Almeida. Comentários à ADPF n. 101: o caso dos pneus remoldados. Revista de Direito dos Monitores da UFF n. 7, 2010, p. 107 e ss. Disponível em: <www.uff.br/rdm>. Acesso em: 20 fev. 2012. OLIVEIRA, Gustavo da Gama Vital. Notas acerca das emendas constitucionais em matéria tributária e financeira. Revista Carioca de Direito, n. 1, p. 53-73, 2010.

SAMPAIO, José Adércio Leite. A Constituição reinventada pela jurisdição constitucional. Belo Horizonte: Del Rey, 2002. SOUZA NETO, Cláudio Pereira de. Mandado de injunção: efeitos da decisão e âmbito de incidência. Interesse Público, v. 43, p. 97-116, 2007.

; FERREIRA, Gustavo Sampaio Telles; LEGALE FERREIRA, Siddharta; SOUZA, Taiguara Líbano

Soares e; SILVA, Anna Carolina Pinheiro da Costa. O ano do direito constitucional. Revista de Direito do Estado, v. 9 , p. 3-20, 2008.

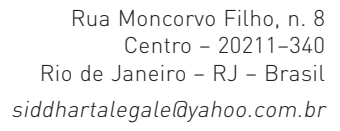

siddhartalegalelayahoo.com.br

Rua Presidente Pedreira, n.62 Ingá - 24210-470

Niterói - RJ - Brasil

ericbdfernandesagmail.com

\section{Siddharta Legale Ferreira}

Mestre em Direito Constitucional pela Universidade FEDERAL Fluminense

Professor substituto de Direito Internacional Público na Universidade FEDERAL do RIO dE JANEIRo (UFRJ)

Professor substituto do Departamento de Direito Público da Universidade Federal Fluminense (UFF)

Advogado

\section{Eric Baracho Dore Fernandes}

\author{
Mestrando em Direito Constitucional \\ PELA Universidade FEDERAL Fluminense (UFF) \\ Pós-graduado em Direito Público, \\ em Direito Processual e em Direito Privado \\ PELA Universidade CÂndido Mendes (UCAM) \\ Pós-graduando PEla Escola da Magistratura \\ do Estado do RIO de Janeiro (EMERJ)
}

Advogado 
